\title{
TECHNICAL IMPROVEMENT IN REVOLUTION CONTROL EXPRESSED THROUGH PROCESS CAPABILITY INDICES
}

\begin{abstract}
In today's competitive environment, it is essential that the company has a set of key indicators reflecting its credible performance. Modern concepts of measuring corporate performance emphasize the need for not only financial but also non-financial indicators that allow us to create a dynamic picture of the competitive situation on the market and help us to link the short-term performance to the long-term strategic vision of the company. This area can also include the issue of the numerical evaluation of the benefits brought about by using new technology in the enterprise when compared with the previously used technology. As an example, we show the modernization of equipment and the possibility of expressing the quality of a design change described on an experimental stand used for the research of the disintegration process.

The stability of the input variables crucially affects the course of the experiment, the results and the subsequent models formation. To assess the quality of the measured values a suitable method searched for their numerical evaluation. It was found that this can be done through a process capability index, as a measure of the quality of the monitored process, and an application of the process capability index is one of the possibilities for such evaluation.
\end{abstract}

Keywords: Input and output variables of the system, process capability index, evaluation of measurements.

\section{Introduction}

An application of high voltage semiconductor devices (diodes, thyristors, diacs, triacs, transistors) in the late seventies and early eighties of the last century in the industry meant a qualitative change in the technical solutions in many areas of industry and in mostly it had significant economic consequences. However, the most significant impact it had was in the field of control technology and automatic control. For decades the technical solutions as well as the parameters of these devices were suitable. They worked accurately, reliably and for the operation were satisfactory. But the current economic and environmental conditions and new technologies require advanced technical solutions often based on industrial PCs and the hardware and software. They almost ensure a step change in quality control. The technical changes often have large capital requirements for funding projects, producing documentation and commissioning it. The more complex a new technology is, the more difficult it is to express the benefits and it is often missing the appropriate means for the exact (sophisticated) expression. One solution may be a new level of quality representation using process capability indices (PCI).

Examples of their use can be calculating the PCI before and after the structural change of control of the experimental stand in a laboratory of the Institute of Geotechnics of the Slovak Academy of Science (UGT SAV in Kosice). The experimental stand is used to study the process of disintegration of rock by drilling tools used in practice, up to a diameter of $54 \mathrm{~mm}$. A detailed description of the stand is in [1]. In this paper we pay particular attention to the control of revolutions as the input variable of the system indentor-rock before and after the technology stand reconstruction, which should have ensured the greater stability of the input variables. Given the complexity of the experimental stand (Fig. 1) and the experiment itself, we will show examples of using capability indices to control the revolutions by the original method based on high-voltage semiconductor devices and after the stand reconstruction.

\section{A system to ensure controllable revolutions}

The original manual control or continuous revolution control of a DC electric motor with the drive type Ward Leonard was replaced by a revolution control with a frequency converter. The original DC electric motor with a power of $12.5 \mathrm{~kW}$ was replaced by a new asynchronous motor with an output of $22 \mathrm{~kW}$. The initial revolution control range $0-24 \mathrm{~s}^{-1}$ was replaced by a control with a unistor range from 0 to $33.3 \mathrm{~s}^{-1}$. The drilling tool (indentor)

\footnotetext{
* ${ }^{1}$ Jozef Futo, ${ }^{2}$ Lenka Landryova, ${ }^{2}$ Vladena Baranova

${ }^{1}$ Institute of Control and Informatization of Production Processes, Faculty of Mining, Ecology, Process Control and Geotechnology,

Technical University of Kosice, Slovakia

${ }^{2}$ Department of Control Systems and Instrumentation, VSB - Technical University of Ostrava, Ostrava, Czech Republic

E-mail: jozef.futo@tuke.sk
} 
is driven by an asynchronous motor with a belt and V-belt system. Measurement revolution is provided by a tachodynamo which is on the common axis with a disconnecting tool. According to the values of the output voltage of the tachodynamo, which is in the range of 0 to $10 \mathrm{~V}$, we can determine the instantaneous revolutions of a disconnecting tool. The output of the tachodynamo is calibrated with a stroboscope tachometer with an accuracy of $0.5 \%+2$ digits. The control of the revolution variable of the disconnecting tool spindle is provided by the control computer using a control algorithm which compares the desired revolution input to the system with the real revolution. By the feedback system the frequency converter provides the stable spindle revolution of the disconnecting tool during the experiment.

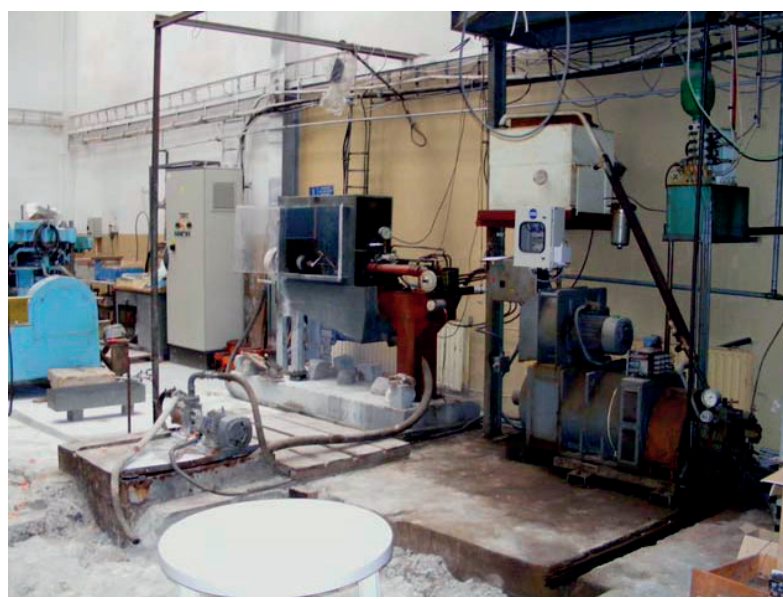

Fig. 1 Experimental stand

For qualitative assessment of input or output process variables it is possible to proceed in several ways. One is the evaluation by Process Capability Index (PCI) which compares the prescribed maximum permissible variability of values given by tolerance limits to the actual variability of the observed character achieved by a statistically controlled process. Without proper measuring equipment and methodology we are not in a position to determine the capability of processes adequately. This fact was proven as particularly important in the case of the non-standard identification of complex systems when the useful signal represented only a small fraction of the total monitored signal. Statistical control is based on the fact that the specified measured value (revolution) is controlled at appropriate intervals within a selected set of a number of values. Measurement procedure is implemented by a measuring process. By taking into account the specific effects we set the final measured value in the specific range. The size of a range, thus the rate of distraction, expresses a measurement error. If this error is acceptable, measurement uncertainty is low, then we conclude that the measurement process has the capability for those conditions. The aim of research of measurement system capability is a statistical estimate of the rate at which the repeatability and reproducibility misrepresent the evaluated reality $[2,3,4,5,6,7,8,9$ and 10].

\section{Theoretical analysis of the statistical evaluation of the quality of the measurement process}

Statistical control of the measuring process can be understood as the maintenance of its statistically controlled status. This would ensure the consistency of measurement results with specific requirements for measurement. We assume that the behavior of the measuring process describes the behavior of multiple output values, compared with the established criteria. The basic statistical control tool for measuring processes is the control chart [1, 11 and 12].

The theory of control charts is based on differentiating between two types of variability. The first type is a random variability due to random causes. This type produces a wide range of unidentified causes. Each contributes with a small component of the total variability, but none of them contribute significantly to it. The second type of variability is a real change in the measuring process. Such a change may be caused by some identifiable causes which are not a part of the internal measuring process and can be, at least in theory, removed. These causes can be systemic and can be attributed to the use of measuring devices, the methods and procedures of measurement, measurement conditions, measuring staff, and similar.

For the experiment of rock disintegration in the laboratory of UGT SAV in Kosice the previous control of revolution was replaced by an automatic control. Then, it was necessary to find a suitable (mathematical) tool for a quantitative assessment of the structural changes and for the numerical evaluation. One option seems to be the use of the process capability index. Data from control charts are available to calculate the necessary PCI. It is necessary to take into account the specific use of relationships, since the calculated indices change values according to the input process parameters.

\section{Process capability}

The role of the PCI is simply to express the relationship between the target setpoint-T (Target Value), specified limits LSL and USL (Lower/Upper Specification Limit) and the actual process value expressed by the mean $\mu$ and standard deviation $\sigma$ of the measured values of the selected quality parameter of the process. The target value $\mathrm{T}$ is the desired mean of the quality parameter that needs to be achieved, or approximately achieved.

The lower and upper specific limits LSL and USL are the limits set for the quality parameter with respect to the required variability in order to ensure the desired functionality of the process [2, 3, 9, 10, 11 and 12]. 
To evaluate the processes various indices were gradually developed. According to the number of monitored quality parameters they can be divided into:

- single parameter indices,

- several simultaneously monitored quality parameter indices.

\section{Using capability indices to determine the quality of the measured values}

For practical interpretation it is important to accurately select a combination of indices, therefore, not consider those, for which the conditions are not met, and complete them with graphical representation of the distribution of the monitored quality parameter, a target value and specific limits. In Fig. 2 7 we can observe the courses of revolution with the changing target value $n=1000 \mathrm{~min}^{-1}$, and $n=1500 \mathrm{~min}^{-1}$ respectively, and the required tolerance range with the range of values $\pm 1 \%$, and $\pm 5 \%$ respectively. These courses were obtained experimentally at various monitored process modes and simulations. When compared they vary in the random variable characteristics (mean, standard deviation, covariance function), but they do not give an adequate overview of the correlation of the required (target) value, mean, the required tolerance and standard deviation.

Assessment of the characteristic of monitored signals (values) is based on the assumption that the input variable - revolution must be constant. However, such an assumption cannot be reached under real conditions (the experimental stand), so determination of the stability of the observed variable is based on the theory of control charts.

The basis of a control chart is to display data in a twodimensional coordinate system. The figures show three criteria: Center Line (CL), Upper/Lower Control Limits (UCL and LCL), and it is recommended that the so-called Upper/Lower Warning Limits (LWL/UWL) are also shown. These limits are calculated as three or two multiplications of the standard deviation of the observed value [13].

In Fig. 2, 3, 5 and 6 we can monitor the revolution with the original control method applied and in Fig. 4 and 7 the revolution with the automatic control after the design change. Control charts are completed by a Target Value - the required revolution value $\mathrm{T}$, and the required tolerance range LSL/USL, which has a range of values of $\mathrm{T} \pm 1 \%, \pm 5 \%$ respectively.

A common feature of the control chart is that all the courses are in the range of $\mathrm{CL} \pm 3 \sigma$, so taking these criteria into account; revolution was statistically stable and suitable for further processing. The tolerance range of $1 \%, 5 \%$ respectively, was exceeded several times; therefore, the original experimental stand did not meet the demands of further experiments. This problem was solved by a change in constructional design, as it can be observed in Fig. 4 and 6. Comparison of required and output values of each characteristic can be observed in Table 1 which, however, does not give an overview of the quality achieved (the quality of measured values), and based on these values it does not show whether or not the input signal of the system is suitable for further use.

\section{6. $C_{p m}$ Capability Index}

Capability index $\mathrm{C}_{\mathrm{pm}}$, called Taguchi capability index, removes some of the problems of $\mathrm{C}_{\mathrm{p}}$ and $\mathrm{C}_{\mathrm{pk}}$ indices and keeps their good properties. Index $\mathrm{C}_{\mathrm{p}}$ characterizes the variability of the process, but does not say how it was actually used. Its disadvantage is that it does not take into account the center of the distribution of measured values with respect to the desired target value $\mathrm{T}$ and requires both tolerance limits to be entered. Index $C_{p k}$, unlike $C_{p}$ index, considers not only variability, but also the location of the monitored values of the quality parameter in the tolerance field. Thus, it characterizes the true process capability to follow the prescribed tolerance limits.

Index $C_{p m}$ was designed in relation to the loss function used in the Taguchi approach for a quality assessment. It compares the maximum permissible variability of observed quality parameter specified by a tolerance range width and the actual variability around the target value $T$ :

$C_{p m}=\frac{U S L-L S L}{6 \cdot \sqrt{\sigma^{2}+(\mu-T)^{2}}}$

The term $\left\{\sigma^{2}+(\mu-T)^{2}\right\}$ is a measure of the average quadratic loss caused by a failure to comply with the terms of production quality. If the standard deviation increases and/or the mean moves away from the Target value, the denominator of an index increases and $C_{p m}$ index value decreases. The advantage of this index is its ability to record the changes of a mean that are "compensated" in the index $C_{p k}$ by changing the standard deviation. This index is used for two-sided tolerances and a target located in the center of the tolerance range, as is the case in our application [14 and 15].

After calculation of capability indeces $C_{p m t 1} \mathrm{aC}_{p m t 5}$ (tolerance of input variable is 1 , resp. $5 \%$ ) these factors are taken into account, capability indices are calculated and the increasing value of the coefficient is representing the increasing quality of the input variable as well (Table 1). 


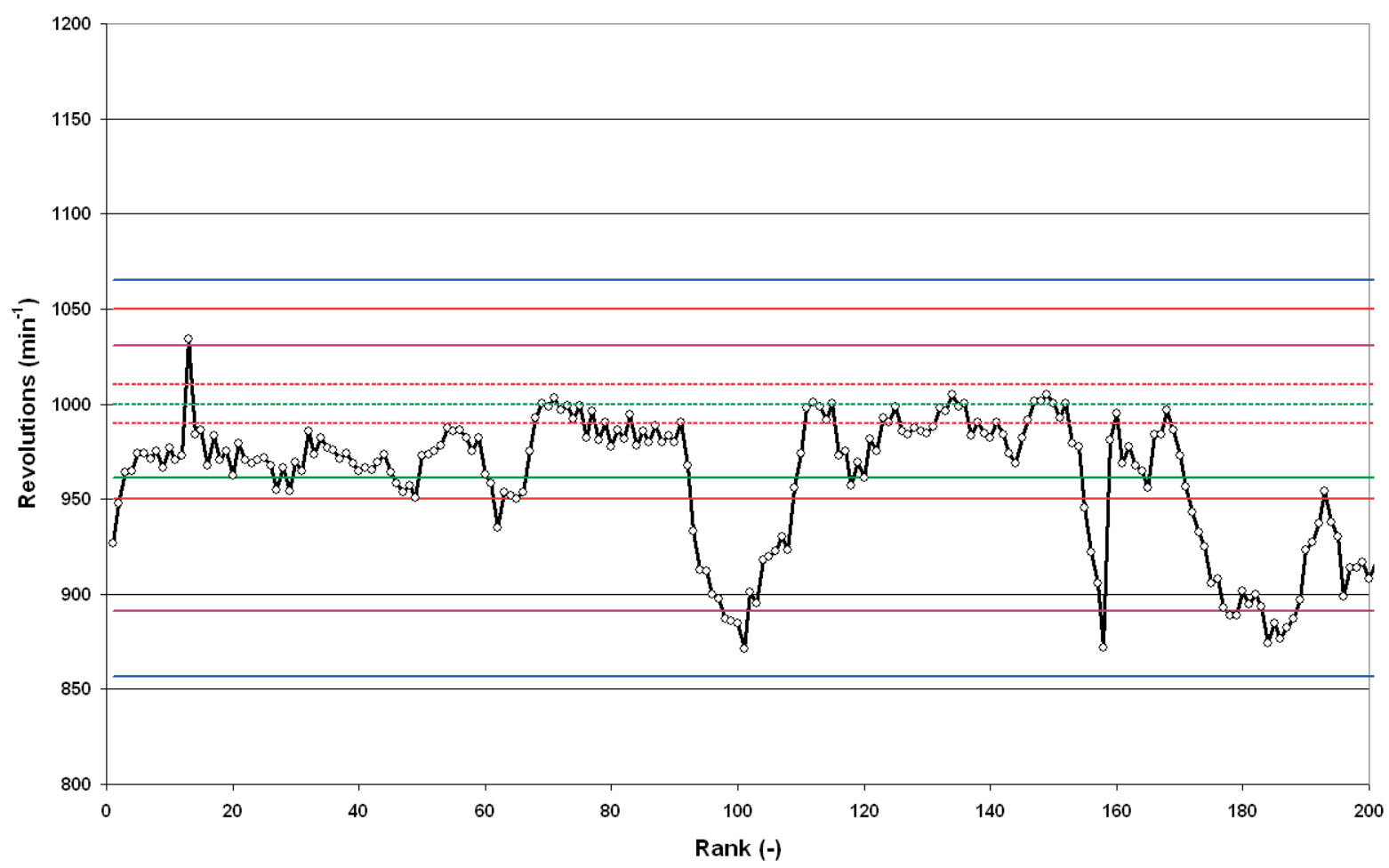

$-\infty$ Revolutions - $\mathrm{CL}-\mathrm{UCL}-\mathrm{LCL}-\mathrm{UWL}-\mathrm{LWL} \quad-\mathrm{T} \quad-\mathrm{USL} 1 \% \quad-\mathrm{LSL} 1 \%-\mathrm{USL} 5 \%-\mathrm{LSL} 5 \%$

Fig. 2 Revolution course for the previous stand design with manual control and higher pressure (2004)

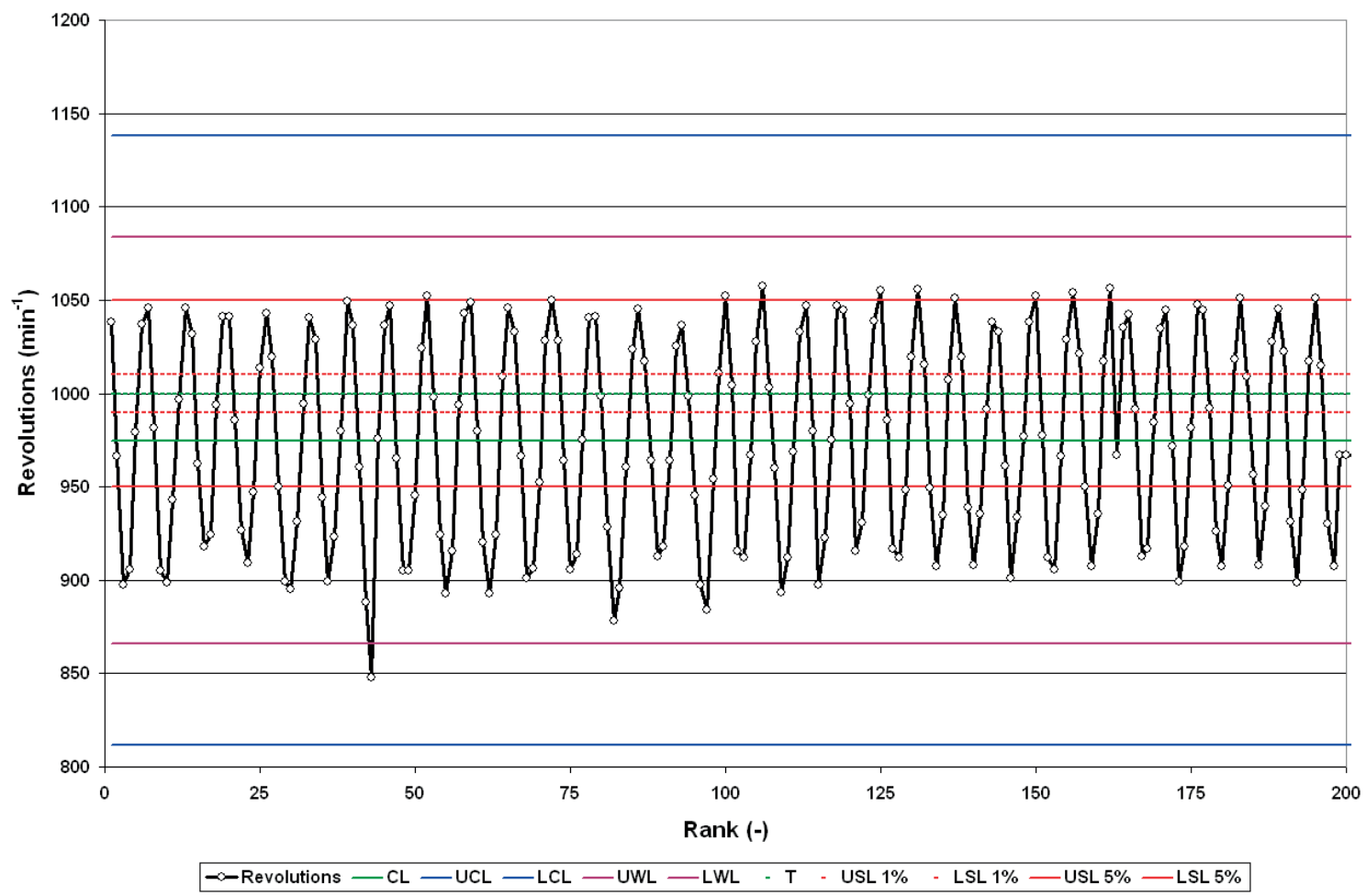

Fig. 3 Revolution course for the previous stand design with manual control and lower pressure (2004) 


\section{COMMNICOIIONS}

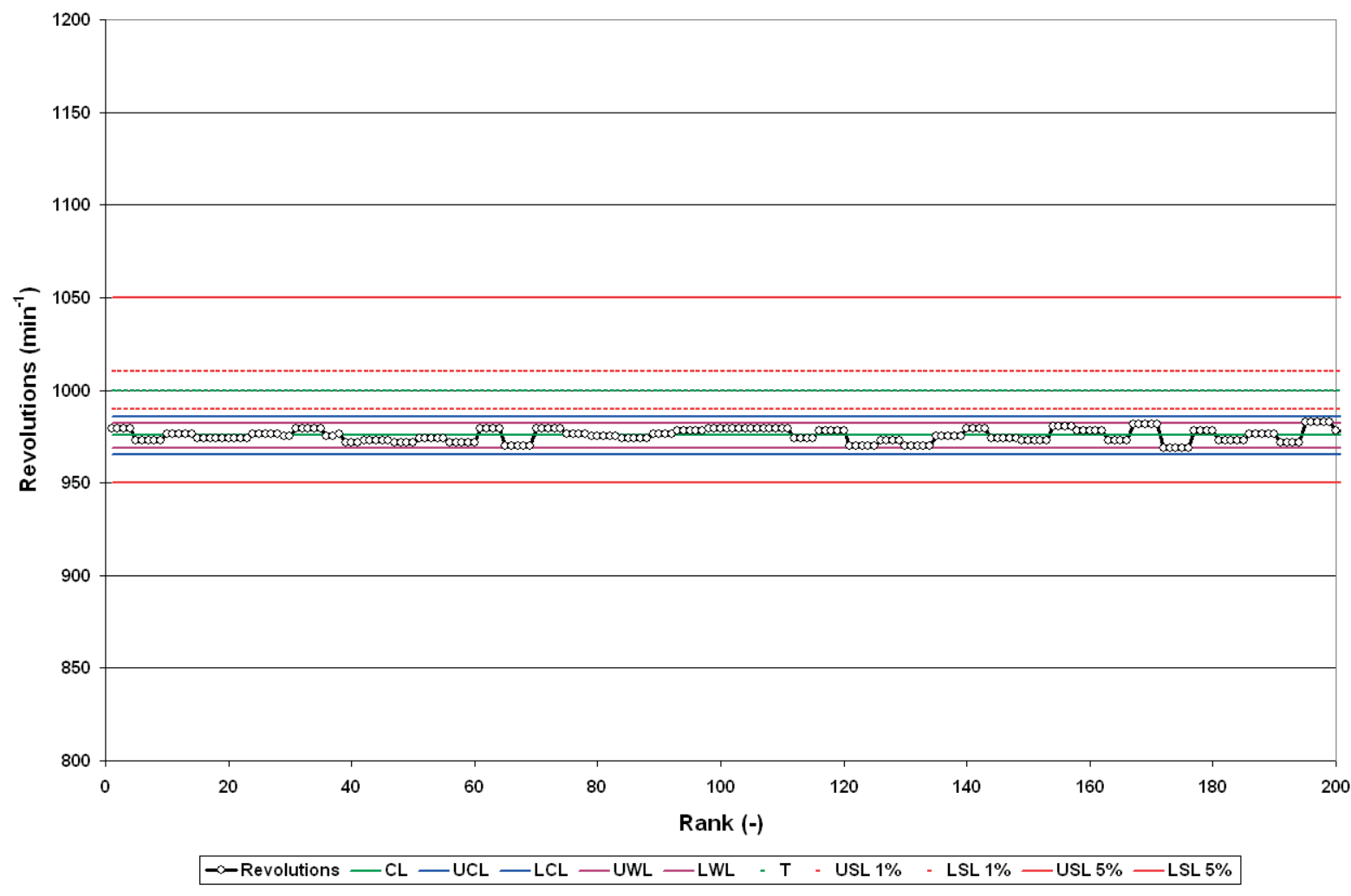

Fig. 4 Revolution after the constructional change of design with automatic control (2012)

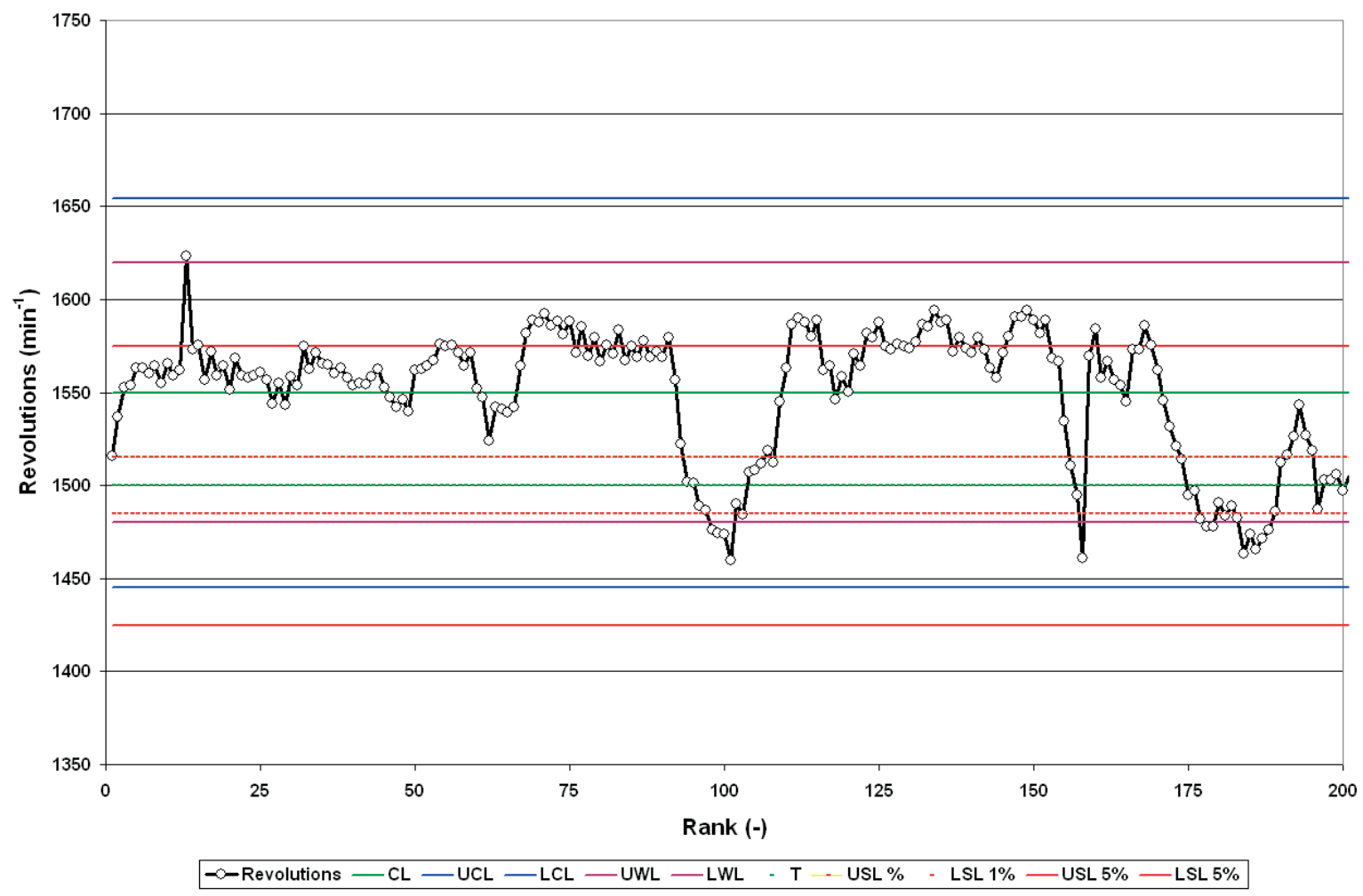

Fig. 5 Simulated revolution course for the previous control and higher pressure (2004) 


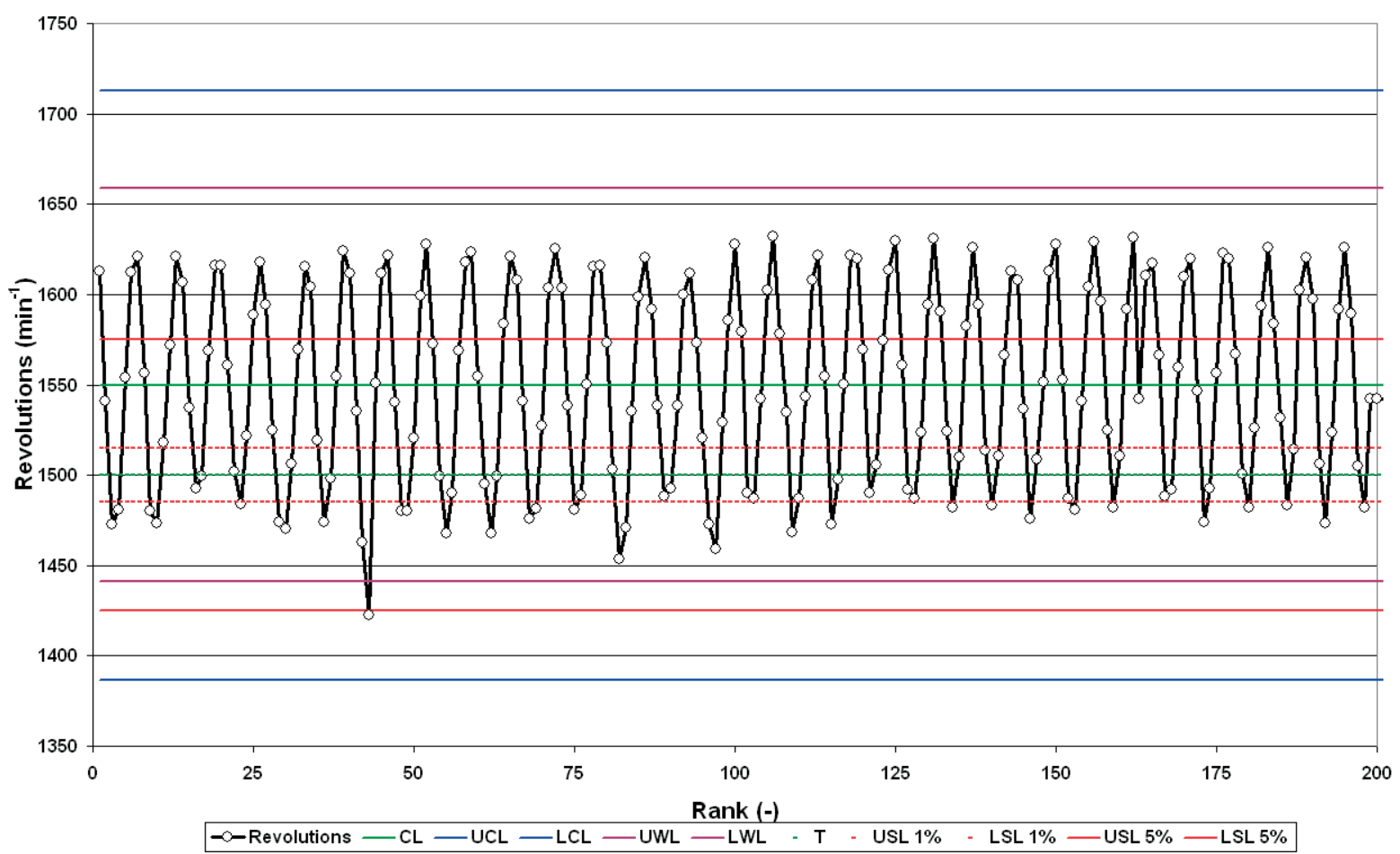

Fig. 6 Simulated revolution course for the previous control and lower pressure (2004)

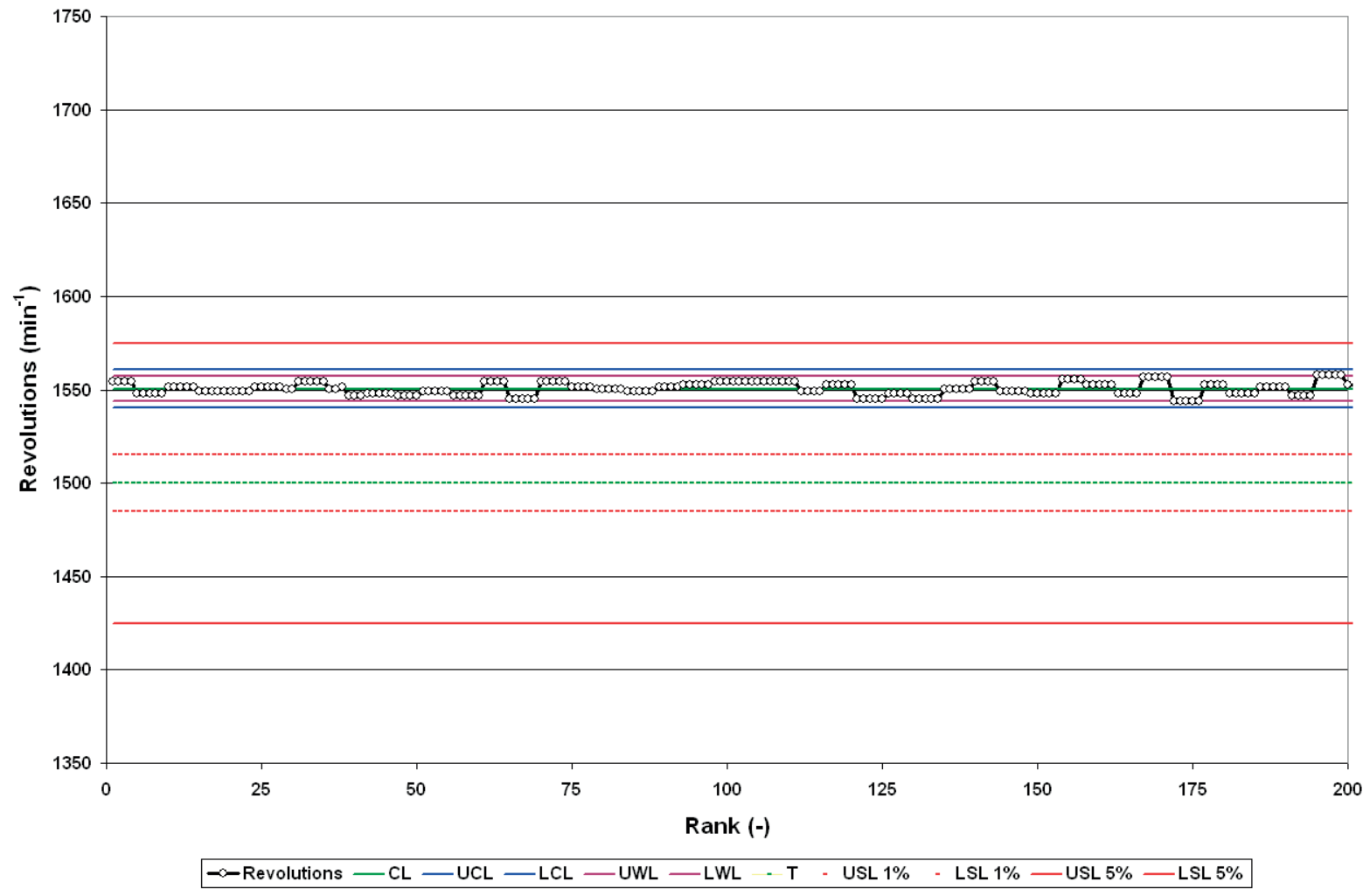

Fig. 7 Revolution course after the constructional change of design with automatic control (2012) 
Characteristics and quality criteria of measured variable - revolution

Table 1

\begin{tabular}{|c|c|c|c|c|c|c|}
\hline Criteria & $\begin{array}{c}\text { Revolution }\left(\mathrm{min}^{-1}\right) \\
\text { (Fig. 2) }\end{array}$ & $\begin{array}{c}\text { Revolution }\left(\mathrm{min}^{-1}\right) \\
\text { (Fig. 3) }\end{array}$ & $\begin{array}{c}\text { Revolution }\left(\mathrm{min}^{-1}\right) \\
\text { (Fig. 4) }\end{array}$ & $\begin{array}{c}\text { Revolution }\left(\min ^{-1}\right) \\
\text { (Fig.5) }\end{array}$ & $\begin{array}{c}\text { Revolution }\left(\min ^{-1}\right) \\
\text { (Fig. 6) }\end{array}$ & $\begin{array}{c}\text { Revolution }\left(\mathrm{min}^{-1}\right) \\
(\text { Fig. 7) }\end{array}$ \\
\hline CL & 961 & 975 & 975 & 1550 & 1550 & 1551 \\
\hline UCL & 1065 & 1138 & 986 & 1654 & 1654 & 1561 \\
\hline LCL & 856 & 812 & 965 & 1445 & 1445 & 1540 \\
\hline UWL & 1031 & 1084 & 982 & 1620 & 1620 & 1557 \\
\hline LWL & 891 & 866 & 969 & 1480 & 1480 & 1544 \\
\hline T & 1000 & 1000 & 1000 & 1500 & 1500 & 1500 \\
\hline SIGMA & 34.82 & 54.36 & 3.41 & 34.82 & 54.36 & 3.41 \\
\hline USL 1\% & 1010 & 1010 & 1010 & 1515 & 1515 & 1566 \\
\hline LSL 1\% & 990 & 990 & 990 & 1485 & 1485 & 1534 \\
\hline USL 5\% & 1050 & 1050 & 1050 & 1575 & 1575 & 1628 \\
\hline LSL 5\% & 950 & 950 & 950 & 1425 & 1425 & 1473 \\
\hline$C_{\text {pmt1 }}$ & $\mathbf{0 . 0 3 3 4}$ & $\mathbf{0 . 0 2 2 4}$ & $\mathbf{0 . 1 3 4 8}$ & $\mathbf{0 . 0 8 2 2}$ & $\mathbf{0 . 0 6 7 8}$ & $\mathbf{0 . 0 9 8 8}$ \\
\hline$C_{\text {pmi5 }}$ & $\mathbf{0 . 3 1 8 3}$ & $\mathbf{0 . 2 7 8 2}$ & $\mathbf{0 . 6 7 3 9}$ & $\mathbf{0 . 4 1 0 9}$ & $\mathbf{0 . 3 3 8 9}$ & $\mathbf{0 . 4 9 3 9}$ \\
\hline
\end{tabular}

\section{Conclusion}

The results we have obtained by monitoring data from the original measurement and measurement after reconstruction can be formulated as follows:

1. Construction of control charts with the currently used hardware and software is relatively simple, quick and easy,

2. The course of the measured values and their limits based on control characteristics UCL and LCL give a sufficiently accurate picture about the variability of the measured values and the tolerance limits USL and LSL,

3. If corrective action (structural changes) are taken it is possible to see in Figures 4 and 6 a positive expected change in the variability of the monitored quality parameter, or process tolerance limits, which the parameter meets respectively,

4. The Taguchi capability index application in the process of the disintegration of rocks on one of the input parameters of monitored system has served as an example to determine the quality of the process, its use also points to the possibility of a numerical expression of a number of parameters of the evaluated variables,

5. Process capability indices for the reconstructed experimental stand are generally increased more than ten times,

6. This method can also be used for complex processes, technology, such as models of MISO types, determining the Key Performance Indicators whose role is to define and quantify progress towards meeting the objectives of the company.

\section{Acknowledgement}

This contribution was written within the framework of VEGA 1/0729/12, VEGA 1/0295/14 project and specific research project of VSB-TUO No. SP2013/85.

\section{References:}

[1] FUTO, J., IVANICOVA, L., KREPELKA, F.: Hydraulics and Pneumatics - Parts 1-2 (in Slovak), 2010, pp. 9-13.

[2] BENKOVA, M.: Quality Assurance Processes (in Slovak)], Kosice : Technicka univerzita : F BERG, 2007.

[3] BENKOVA, M., FlOREKOVA, L., BOGDANOVSKA, G.: Variability of Quality Parameters and the Loss Function (in Slovak), Acta Montanistica Slovaca, vol. 10, No. 1, 2005, 57-61.

[4] FLOREKOVA, L.: Statistical Methods for Quality Assessment (in Slovak), Acta Montanistica Slovaca, vol. 1, 1998, 1-20.

[5] HANZELOVA, M., FLOREKOVA, L.: Environmental Performance Evaluation. 5 $^{\text {th }}$ intern. Control Conference 2004, Zakopane, May 2004, 915-918, ISBN 83-89772-00-0.

[6] HanZeloVA, M., FloreKoVA, L., BenKoVA, M.: A Protection of Air from the Point of View of Local Producer of Polluting Substances/Emissions, $3^{\text {rd }}$ intern. Control Conference 2002, Malenovice, May 2002, 569-574, ISBN 80-248-0089-6. 
[7] MALINDZAKOVA, M.: Significance Evaluation of Environmental Aspects, Communications - Scientific Letters of the University of Zilina, vol. 13, No. 3, 2011, 48-51, ISSN 1335-4205.

[8] LESSO, I., FLEGNER, P.: Specifications Symptoms of Rock Disintegration Process of Rotary Drilling Control Process (in Slovak), Sbornik vedeckych praci Vysoke skoly banske - Technicke univerzity Ostrava : Rada stavebni, vol. 9, No. 2, 2009, 155-165, ISSN 1213-1962.

[9] LESSO, I. et al.: Research of the Possibility of Application of Vector Quantisation Method for Effective Process Control of Rocks Disintegration by Rotary Drilling, Metalurgija, vol. 49, No. 1, 2010, 61-65, ISSN 0543-5846.

[10] LESSO, I. et al.: New Principles of Process Control in Geotechnics by Acoustic Methods. Metalurgija. vol. 46, No. 3, 200), 165168, ISSN 0543-5846.

[11] PAVLICKOVA, M.: Methodology for Assessing the Quality Parameters of Selected Products, (in Slovak), Dissertation work, Kosice, 2007, TUKE : F BERG.

[12] STN ISO 8258:1995: Shewhart Control Charts, Slovak Technical Standard (in Slovak), Slovenska technicka norma, 1995.

[13] SMITH, D., J.: Reliability Maintainability and Risk, Rochester : Kent, 1997

[14] SMITH, J.: The KPI Book, Insight Training \& Development, 2001, ISBN 978-0-954-02590-8.

[15] PARMENTER, D.: Key Performance Indicators: Implementing, and Using Winning KPIs, John Wiley \& Sons : Inc., Hoboken : New Jersey, 2010, ISBN 978-0-470-54515-7. 